\title{
Appreciation of Entertainment:
}

The Importance of Meaningfulness via Virtue and Wisdom

\author{
Mary Beth Oliver ${ }^{1} \&$ Anne Bartsch ${ }^{2}$ \\ ${ }^{1}$ Penn State University, University Park, PA \\ ${ }^{2}$ Martin Luther University Halle
}

Oliver, M. B., \& Bartsch, A. (2011). Appreciation of entertainment: The importance of meaningfulness via virtue and wisdom. Journal of Media Psychology, 23(1), 29-33. doi: $\underline{10.1027 / 1864-1105 / a 000029}$

The definitive version is available at http://psycontent.metapress.com/content/q2lq7n7278rri23x/?p=7915b9ec8b694801acaaeee10b72177f $\underline{\text { p } \mathrm{i}=5}$

This article may not exactly replicate the final version published in the previously mentioned Journal. It is not the version of record and is therefore not suitable for citation.

\section{Acknowledgements: -}

Funding: -

Corresponding author: mbo@psu.edu 


\begin{abstract}
The purpose of this essay is to examine the experience of appreciation to media entertainment as a unique audience response that can be differentiated from enjoyment. To those ends, the first section provides a conceptualization of appreciation in which we outline how we are using the term and how it is distinct from questions of emotional valence. The second section discusses the types of entertainment portrayals and depictions that we believe are most likely to elicit feelings of appreciation. Here, we suggest that appreciation is most evident for meaningful portrayals that focus on human virtue and that inspire audiences to contemplate questions concerning life's purpose. In the final section we consider the affective and cognitive components of appreciation, arguing that mixed-affective responses (rather than bi-polar conceptualizations of affective valence) better capture the experience of appreciation and its accompanying feelings states such as inspiration, awe, and tenderness.
\end{abstract}

Keywords: appreciation, elevation, virtue, meaningfulness, gratification 


\section{Appreciation of Entertainment:}

The Importance of Meaningfulness via Virtue and Wisdom

The concepts of enjoyment and entertainment are so closely related that it seems that the words go hand-in-hand. Enjoyment is generally understood to be the motivation for entertainment consumption, the yardstick by which quality entertainment is judged, or the primary audience response that encapsulates the entertainment experience. Indeed, for a person to say that he or she did not enjoy some form of entertainment is understood as suggesting that either the experience of consumption itself was less than gratifying in some way or that the entertainment fare itself was somehow inferior or lacking.

In this essay we do not mean to challenge the importance of enjoyment as descriptive of many forms of viewers' reactions. Rather, the goal of this article is to suggest that the identification of additional types of audience response — namely appreciation — may help account for some of the limits associated with a focus on enjoyment exclusively. To those ends, this essay first considers distinctions between enjoyment and appreciation, then turns to the types of entertainment characteristics that may be particularly likely to elicit appreciation, and finally considers the phenomenology of appreciation in terms of its affective elements.

\section{Enjoyment Versus Appreciation}

Typically, within the field of media psychology, the notion of audience enjoyment has been strongly tied to hedonic considerations and has therefore tended to place emphasis on the positive valence that is thought to accompany or define enjoyment. Likewise, many of the most notable theories of entertainment psychology (e.g., disposition theory, mood-management 
theory) have identified (or implied) that hedonically positive affective experiences are part-andparcel of audience enjoyment (Raney, 2003; Zillmann, 1988, 2000).

Although enjoyment ala positively valenced responses may well account for the vast majority of the most typical forms of entertainment that individuals consume on a day-to-day basis (e.g., television sitcoms, variety programming, etc.), it is evident that joy, mirth, or joviality are not the only affective reactions that elicit gratification. A number of researchers have recently provided explications for the concept of enjoyment that not only notes its complexity, but that also "allow for" enjoyment that is not necessarily characterized in terms of positive affect. For example, Bartsch, Vorderer, Mangold, and Viehoff (2008) conceptualized the entertainment experience in terms of meta-emotions, arguing that the appraisal of responses experienced during entertainment (including positive and negative emotions) form the basis of gratification (see also Vorderer, Klimmt, \& Ritterfeld, 2004). More recently, Tamborini, Bowman, Eden, and Grizzard (in press) applied the general concepts of self-determination theory (SDT) (Ryan \& Deci, 2000) to argue that enjoyment of entertainment can be most generally conceptualized not in terms of the valence of the experience, but rather in terms of the fulfillment of needs, including both lower-order needs that may be most akin to hedonic needs, and higher-order, intrinsic needs such as autonomy, competence, and relatedness.

With these more recent conceptualizations of enjoyment in mind, it is clear that scholars are moving toward a greater distinction between the direct affective responses that viewers may have in reaction to entertainment (e.g., humor from a comedy, fear from a thriller) and the gratification that viewers may experience. In other words, researchers now typically readily recognize that material that may be more somber or that fails to elicit immediate feelings of pleasure may be deeply gratifying nevertheless. 
Recently, we proposed that entertain scholars would benefit from making a conceptual distinction between enjoyment (as commonly understood) and appreciation-not only as a means of resolving the seeming paradox of "the enjoyment of tragedy," but also as a means of broadening the scope of what entertainment gratification can represent (Oliver \& Bartsch, in press). To those ends, we conducted several studies to develop and validate measures of enjoyment and appreciation. Together, these studies suggested that enjoyment appears to be most closely associated with hedonic concerns, including experiences of fun and amusement, whereas appreciation appears to be more closely associated with concerns related to meaningful entertainment experiences. Specifically, appreciation of films included both cognitive and affective responses as reflected in items such as "I found this movie to be very meaningful," "I was moved by this movie," and "The movie was thought provoking."

It is important to note that in developing these scales we did not conceptualize enjoyment and appreciation as opposite ends of a continuum. Consistent with this reasoning, our measures of enjoyment and appreciation were uncorrelated under some circumstances such as when participants recalled and rated the most recent movie they had seen as part of their everyday media diet $(.04<r<.09)$, but were strongly correlated among participants rating a film classic they had just watched as part of a film class $(.50<r<.79)$. Based on these findings, it seems reasonable to suggest that some forms of entertainment may elicit high levels of both appreciation and enjoyment (e.g., an engaging, meaningful film), some may elicit enjoyment but not appreciation (e.g., a fun but shallow "guilty pleasure"), some may elicit appreciation but not enjoyment (e.g., a somber but moving depiction), and some may elicit neither (e.g., a bad film!). With this conceptualization of appreciation as an additional dimension of audience response 
differentiated from enjoyment, the next section more closely considers the characteristics of entertainment content that may give rise to appreciation.

\section{The Nature of Appreciated Entertainment}

Given the apparent distinction between enjoyment and appreciation, what might best characterize the different types of content that gives rise to these responses? Perhaps one criterion that first comes to mind is the artistic or creative talent reflected in the entertainment. Consistent with this reasoning, Oliver and Bartsch's (in press) research showed that perceptions of artistic value were more strongly related to appreciation than to enjoyment. However, their factor analyses found that items reflecting aesthetic appeal cross loaded on both appreciation and enjoyment measures. These findings may imply that whereas perceived aesthetic talent is a necessary component of appreciation, even some "shallow" films (e.g., an action film filled with impressive special effects) may be perceived as artistically valuable on some level.

In addition to artistic value, Oliver and Bartsch's (in press) research utilized the genres of films as a means of validating responses of enjoyment and appreciation. Perhaps not surprisingly, enjoyment tended to be higher for light-hearted, comedic films (e.g., The Wedding Crashers), whereas appreciation tended to be higher for more somber fare (e.g., A Beautiful Mind). In many respects, this finding makes a great deal of sense-after all, if the word "enjoyment" conjures up notions of positive, pleasant affect, then the use of this term to describe entertainment experiences seemingly devoid of this response seems misplaced. Likewise, looking at the list of films in this research that were identified as particularly appreciated by viewers (e.g., Schindler's List, Crash, and Hotel Rwanda), it is tempting to conclude that appreciation is most relevant for entertainment that elicits sadness or grief-a conclusion that may help address theoretical puzzling over the appeal of tragic entertainment (Zillmann, 1998). 
Although "sadness" may be one correlate of appreciation, we believe that it may be too narrow of a descriptor-an argument that we will discuss further in the last section of this essay concerning viewer response (cf., Oliver, 2008). That is, although sad or tragic portrayals may be one type of portrayal that is associated with higher levels of appreciation, we contend that sad depictions are neither sufficient nor necessary conditions for appreciation. First, they are not sufficient, as there are numerous examples where sadness is the intended or primary affective reaction to some entertainment fare, but rather than being appreciated, are more aptly described as "silly," "manipulative," or "melodramatic"—names often used to refer to "chick flicks" such as Steel Magnolias or Beaches. Second, sadness as the defining precursor to appreciation is also not necessary, as there are also examples of films that are not focused on grief or tragedy but that appear to be deeply appreciated (e.g., It's a Wonderful Life).

Rather than focus on the tragic or sad nature of entertainment fare that elicits appreciation among viewers, we believe that it is more fruitful to characterize such entertainment in terms of its meaningfulness. Of course, this statement begs the question-What is meaningful? Questions concerning the nature of meaningfulness are obviously gargantuan, and are therefore perhaps more readily addressed by philosophers than by media scholars. As such, ancient philosophical writings provide one context for addressing this question. Specifically, Aristotle's (trans. 1931) distinction between hedonic versus eudaimonic happiness may be interpreted, in part, in terms of meaningfulness. In contrast to hedonic happiness that reflects more superficial or base states best described in terms of the experience of pleasure and the absence of pain, eudaimonic well-being is characterized as living a "just" or fulfilled life that is characterized in terms virtue guided by practical reason. In this sense, eudaimonic happiness (or flourishing) depends upon living a life that embodies moral virtues noted by Aristotle such as justice, courage, gentleness, generosity, 
and truthfulness; and intellectual virtues, such as knowledge, wisdom, and intuition, that allow for recognition of moral virtues.

Placed in the context of entertainment, one way that "meaningfulness" may be conceptualized is via reference to eudaimonic concerns (Oliver \& Raney, 2008). Specifically, entertainment may be understood as increasingly meaningful to the extent to which it focuses on questions of human moral virtues, it demonstrates such virtues (or the ramifications of the lack thereof), it teaches or inspires insight into such virtues, or it causes the viewer to contemplate such virtues and what it means to live a "just" or "true" life. As such, a film such as To Kill a Mockingbird can be characterized as meaningful through its depiction of wisdom and justice, Saving Private Ryan through its depiction of courage, and even Field of Dreams through its depiction of generosity and gentleness. In contrast, entertainment that appeals to more hedonic concerns may be enjoyed to the extent that it elicits feelings of pleasure and wishful fulfillment of needs and desires that don't necessarily stand the test of reason and moral scrutiny (e.g., Superman, or a kitschy love story).

Ultimately, then, one plausible characteristic of content that gives rise to feelings of appreciation is meaningfulness, with meaningfulness conceptualized in eudiamonic terms via the extent to which the entertainment fare inspires the viewer to consider questions regarding human virtue and life's purpose. It is important at this point to note that our application of eudaimonic concerns to media experiences is more narrow than other researchers' conceptualizations of nonhedonic need satisfaction. For example, Tamborini et al. (in press) and Vorderer and Ritterfeld (2009) draw from conceptualizations of eudaimonia as employed by self-determination theory (SDT), which treats eudaimonic happiness as the fulfillment of intrinsic needs (for a full discussion of SDT's conceptualization of eudaimonia, see Ryan, Huta, \& Deci, 2008). From this 
perspective, then, Tamborini et al. predicted and found support for the idea that various elements of the gaming context (e.g., player controls, social game play) contributed to feelings of greater fulfillment of intrinsic needs (e.g., feelings of competence, autonomy, relatedness), with these feelings, in turn, related to higher levels of self-reported enjoyment.

Our use of the concept of eudaimonia shares with these alternative conceptualizations of non-hedonic need satisfaction the idea that feelings of pleasure or positive valence are not a necessary condition for entertainment to be experienced as fulfilling or gratifying. It is important to note, however, that although both eudaimonia (as we are employing the term) and selfdetermination are dealing with non-hedonic "higher-order" needs, these concepts may be distinct, and their theoretical interrelationship has yet to be explored on conceptual or empirical grounds. Future research using different measures that tap into non-hedonic needs and gratifications (e.g., Oliver \& Bartsch, in press; Oliver \& Raney, 2008; Ryan et al., 2006) might help elucidate this theoretical issue. For instance, it should be possible to test Tamborini et al.'s (in press) suggestion that the concept of eudaimonia as discussed by Oliver (2009) is akin to the autonomy need in SDT. An alternative outcome from such a test might suggest that other than needs for autonomy, competence, and relatedness - the fulfillment of which contributes to enjoyment (cf., Tamborini et al., in press), the fulfillment of eudaimonic needs is associated with a distinct experiential quality that may best be characterized as appreciation (cf., Oliver \& Bartsch, in press). Indeed, we believe that such an outcome may be possible, as the current operationalizations of higher-order needs as associated with SDT seem to focus on the self (as the name implies), whereas our conceptualization of eudaimonia has a more transcendent focus that puts individual need satisfaction into perspective with regard to questions of human purpose and life meaning 
In referring to these alternative conceptualizations of eudiamonic concerns, we do not want to suggest that the articulation of intrinsic needs is too broad or that the fulfillment of such needs isn't gratifying. Indeed, we find it very plausible that motion-controllers lead to feelings of greater competence, and hence greater enjoyment, when playing a video game. What we do want to suggest, however, is that although the fulfillment of many needs via media engagement, including different intrinsic needs, may be characterized in terms of enjoyment, our more narrow conceptualizations of appreciation and eudiamonic concerns rest on perceived meaningfulness, moral considerations, and contemplations of life's purpose. The consumption of media content that is devoid of such portrayals may be fulfilling and hence enjoyed, but we are not certain that it would be appreciated in the same way that we are using the term. Perhaps one way to illustrate our distinction is by asking, "To what extent are you inspired to contemplate meaningful life questions, or motivated to become a better person having [read that book, seen that film, watched that TV-program, played that game, etc.]?

Although our focus on and conceptualization of eudaimonia in terms of meaningfulness may represent only one of several higher-order needs, we suggest that entertainment that addresses questions of life's purpose and human virtue is unique and deserving of special consideration about what it does and does not share with the fulfillment of other intrinsic needs. We have argued here that it is the contemplation of meaningfulness via human virtue that forms the basis of appreciation. Importantly, too, we believe that the experience of appreciation as we have conceptualized it is associated unique affective and cognitive responses, and important motivational outcomes. Consequently, the last section of this essay considers the phenomenology of appreciation.

\section{The Experience of Appreciation}


A great deal of entertainment fare is described in terms of identifiable, discrete, primary emotions: thrillers elicit fear, tear-jerkers elicit sadness, comedies elicit joy, etc. Furthermore, the valence of affective responses is often conceptualized (and hence operationalized) in bi-polar terms - if a viewer experiences high levels of positive affect, he/she, by definition, experiences low levels of negative affect.

Given these typical conceptualizations of affective responses, it is not completely surprising that the experience of appreciation is often thought to be tied more closely with sad than happy affect, as contemplations of life meanings (e.g., justice, honesty, courage) may force us to confront not only how our own lives may fail to live up to such virtues, but also how our own lives are fleeting opportunities to strive for such fulfillment. As a result, although we may appreciate grappling with these questions concerning life's meanings-if for no other reason than contemplation of such virtues may help us move toward a greater understanding of life's purpose (i.e., what it means to live a just and full life)—such introspection may result in sad or melancholic cognitive and affective experiences.

In contrast to this explanation that focuses on sadness specifically, we believe a more fruitful direction of research is to reconsider the utility of conceptualizing affective and cognitive responses in terms of bi-polar valence. Specifically, conceptualizing (and operationalizing) affect in terms of positive or negative responses fails to capture a diversity of subtle yet powerful affective states that are described using terms such as "poignant," "emotional," "inspiring," "moving," or "touching." Though these types of affective states have yet to garner much empirical attention among media scholars, they are the very ones that one might expect to accompany the consumption of entertainment that grapples with eudaimonic concerns and that hence accompany appreciation. 
Recently, scholars who have begun to study meaningful affective responses have provided evidence for both the importance of moral considerations as instigators of such affect, and for the notion that meaningful affect seems to be best described in terms of mixed valence. For example, Haidt's (2003) research on "moral emotions" identifies a state that he calls "elevation." Elevation, which is similar to notions of inspiration, is broadly characterized as feeling emotional or moved in response to "seeing humanity's higher or better nature" (p. 864), including such acts as kindness, sacrifice, and loyalty. Importantly, though Haidt and his colleagues generally characterize feelings of elevation as positively valenced, such feelings are also recognized to frequently reflect tinges of sadness or bittersweet feelings. Similarly, more recently, Ersner-Hershfield, Mikels, Sullivan, and Carstensen (2008) argued that feelings of poignancy can be conceptualized and operationalized in terms of mixed affect in the face of meaningfulness. These authors defined poignancy as "a mixed emotional experience that occurs when one is reminded of the passing of time during a meaningful experience" (p. 165).

The utility of studying mixed affect to media offerings is only beginning to emerge at this point, though what limited research exists points to its probable role in viewers' appreciation of entertainment. For example, Larsen, McGraw, and Cacioppo (2001) found that people were likely to report feeling both happy and sad after viewing the film Life is Beautiful. Likewise, recent research by Oliver, Limperos, Tamul and Woolley (2009) found that when viewers characterized their reactions to entertainment in terms of meaningful responses (e.g., moved, tender, contemplative), such reactions were associated with the experience of both happy and sad affect simultaneously. Consequently, these emerging studies point to the utility of rethinking of how we conceptualize and operationalize viewers' affective (and cognitive) reactions, and by 
doing so may allow for consideration of a broader and more nuanced array of audience reactions, appreciation included.

Importantly, too, researchers may also consider studying the implications of the experience of appreciation on motivational outcomes. Specifically, Haidt and his colleagues' research (Algoe \& Haidt, 2009; Haidt, 2003) suggests that the experience of elevation via the experience of moral beauty (an experience that we would call "appreciation" in a media context) results in a heightened motivation to be a better person or to help others. Consequently, insofar as the experience of appreciation (as we have defined it) may encourage decidedly pro-social outcomes, future research may explore how to harness such potential for beneficial ends.

\section{Concluding Comments}

The brevity of this essay precludes a more thorough treatment of what is obviously a complex but enriching topic. Our focus here has been on meaningfulness and human poignancies specifically, and therefore other scholars may argue that a broader focus is needed or is more theoretically fruitful. In other words, although we suggest that the meaningfulness of entertainment and hence the appreciation of it rests on the extent to which it encourages grappling with questions of life's purpose in a way that is guided by wisdom and insight, others may argue that such contemplations are but one of several higher-order needs that entertainment may fulfill. At the same time, though, we believe that appreciation is a conceptually distinct experience from enjoyment and self-focused gratification, and that the experience of appreciation is associated with unique cognitive and affective elements, and motivational outcomes. Ultimately, though, we hope that this essay will encourage future work and debate concerning the nature of appreciation, the types of portrayals that elicit this moving response, and the affective states that accompany such deeply inspiring experiences. 


\section{References}

Algoe, S. B., \& Haidt, J. (2009). Witnessing excellence in action: The "other-praising"emotions of elevation, gratitude, and admiration. The Journal of Positive Psychology, 4(2), 105127.

Aristotle. (trans. 1931). Nicomachean ethics (W. D. Ross, Trans.). London: Oxford University Press.

Bartsch, A., Vorderer, P., Mangold, R., \& Viehoff, R. (2008). Appraisal of emotions in media use: Toward a process model of meta-emotion and emotion regulation. Media Psychology, 11, 7-27.

Ersner-Hershfield, H., Mikels, J. A., Sullivan, S. J., \& Carstensen, L. L. (2008). Poignancy: Mixed emotional experience in the face of meaningful endings. Journal of Personality and Social Psychology, 94, 158-167.

Haidt, J. (2003). Elevation and the positive psychology of morality. In C. L. M. Keyes \& J. Haidt (Eds.), Flourishing: Positive psychology and the life well-lived (pp. 275-289).

Washington, DC: American Psychological Association.

Larsen, J. T., McGraw, A. P., \& Cacioppo, J. T. (2001). Can people feel happy and sad at the same time? Journal of Personality and Social Psychology, 81, 684-696.

Oliver, M. B. (2008). Tender affective states as predictors of entertainment preference. Journal of Communication, 58, 40-61.

Oliver, M. B. (2009). Affect as a predictor of entertainment choice: The utility of looking beyond pleasure. In T. Hartman (Ed.), Media choice: A theoretical and empirical overview (pp. 167-184). New York: Routledge. 
Oliver, M. B., \& Bartsch, A. (in press). Appreciation as audience response: Exploring entertainment gratifications beyond hedonism Human Communication Research.

Oliver, M. B., Limperos, A., Tamul, D., \& Woolley, J. (2009). The role of mixed affect in the experience of meaningful entertainment. . Paper presented at the the annual meeting of the International Communication Association, Chicago, IL.

Oliver, M. B., \& Raney, A. A. (2008, May). Development of hedonic and eudaimonic measures of entertainment motivations: The role of affective and cognitive gratifications. Paper presented at the annual convention of the International Communication Association, Montreal, Canada.

Raney, A. A. (2003). Disposition-based theories of enjoyment. In J. Bryant, D. RoskosEwoldsen, \& J. Cantor (Eds.), Communication and emotion: Essays in honor of Dolf Zillmann (pp. 61-84). Mahwah, NJ: Lawrence Erlbaum Associates.

Ryan, R. M., \& Deci, E. L. (2000). Self-determination theory and the facilitation of intrinsic motivation, social development, and well-being. American Psychologist, 55, 68-78.

Ryan, R. M., Huta, V., \& Deci, E. L. (2008). Living well: A self-determination theory perspective on eudaimonia. Journal of Happiness Studies, 9, 139-170.

Tamborini, R., Bowman, N. D., Eden, A. L., \& Grizzard, M. (in press). Defining media enjoyment as the satisfaction of intrinsic needs. Journal Of Communication.

Vorderer, P., Klimmt, C., \& Ritterfeld, U. (2004). Enjoyment: At the heart of media entertainment. Communication Theory, 14, 388-408.

Vorderer, P., \& Ritterfeld, U. (2009). Digital games. In R. L. Nabi \& M. B. Oliver (Eds.), Sage handbook of media processes and effects (pp. 455-467). Thousand Oaks, CA: Sage. 
Zillmann, D. (1988). Mood management: Using entertainment to full advantage. In L. Donohew, H. E. Sypher, \& E. T. Higgins (Eds.), Communication, social cognition, and affect (pp. 147-171). Hillsdale, NJ: Lawrence Erlbaum Associates.

Zillmann, D. (1998). Does tragic drama have redeeming value? Siegener Periodikum für Internationale Literaturwissenschaft, 16, 1-11.

Zillmann, D. (2000). Mood management in the context of selective exposure theory. In M. E. Roloff (Ed.), Communication Yearbook (Vol. 23, pp. 103-123). Thousand Oaks, CA: Sage. 